\title{
Publisher Correction: HIV-1 replication complexes accumulate in nuclear speckles and integrate into speckle-associated genomic domains
}

\author{
Ashwanth C. Francis (D, Mariana Marin, Parmit K. Singh, Vasudevan Achuthan, Mathew J. Prellberg, \\ Kristina Palermino-Rowland, Shuiyun Lan, Philip R. Tedbury, Stefan G. Sarafianos, Alan N. Engelman \& \\ Gregory B. Melikyan (1)
}

Correction to: Nature Communications https://doi.org/10.1038/s41467-020-17256-8, published online 14 July 2020.

The original version of this Article contained several errors in Fig. 7. In Fig. 7a, the PF74 concentration for the middle panel was incorrectly labelled as ' 25 ', rather than the correct ' 2.5 '. In Fig. 7b, the PF74 concentration for the blue series was incorrectly labelled as '25', rather than the correct ' 2.5 '. In Fig. 7c, the PF74 concentration for the third panel from the top was incorrectly labelled as '25', rather than the correct ' 2.5 '. In Figs. $7 \mathrm{~d}$ and e, the PF74 concentrations for the green series were incorrectly labelled as ' 2.5 ', rather than the correct ' 25 '. These errors have all been corrected in both the PDF and HTML versions of the Article.

Published online: 26 November 2020

Open Access This article is licensed under a Creative Commons Attribution 4.0 International License, which permits use, sharing, adaptation, distribution and reproduction in any medium or format, as long as you give appropriate credit to the original author(s) and the source, provide a link to the Creative Commons license, and indicate if changes were made. The images or other third party material in this article are included in the article's Creative Commons license, unless indicated otherwise in a credit line to the material. If material is not included in the article's Creative Commons license and your intended use is not permitted by statutory regulation or exceeds the permitted use, you will need to obtain permission directly from the copyright holder. To view a copy of this license, visit http://creativecommons.org/licenses/by/4.0/.

(C) The Author(s) 2020 